\title{
A Symbol of Healing with Feminine Vitality: The Willow
}

\author{
Kowen, Mee Ra*
}

\begin{abstract}
$<$ Abstract $>$
The symbolism of the willow, with its healing energy for addiction, can be considered in terms of its religious, folkloric, and mythological aspects as in Marion Woodman's book The Ravaged Bridegroom - Masculinity in Women. This study concerned the healing process of a female client formerly obsessed with an addiction not separated from the Self. The client grasped the willow as a symbol of female energy and subsequently was reborn with renewed feminine vitality. The female healing energy of the willow connected her abandoned body to her soul. The vitality of the willow empowered the client to heal her animus of addiction, learn what her body wanted from the boundary of life and death, and realize what her soul desired. Her body, through consciousness raising, truly embraced the deity, or Self, which she had struggled unilaterally before to connect with herself. The totality, created by archetypes, meant a deep base of personality, accepted consciousness and unconsciousness and transcended the ego.
\end{abstract}

Keywords : willow, healing energy, addiction, feminine vitality

* Corresponding author, Director of Ribbon Psychological Counseling Center, Department of Child Counseling and Psychological Therapy, Graduate School of Child Welfare, Namseoul University (kowen0808@naver.com) 
Journal of Symbols \& Sandplay Therapy, Vol.10 No.1.

\section{I . Introduction}

For ages, the willow has been a part of the different scenes that make up our lives. Willows are attracted to moisture, and are easily found in groups near bodies of water. Fung-shui experts use willow branches to locate water veins. Willows are considered sacred and are often present in rituals that are held to ask the heavens for rain. Perhaps this is because the willow symbolizes the season of spring, in which new life begins, and because it is so closely associated with water. Willows were often planted near wells because their roots purify the water by absorbing nitric and phosphoric acid. They were also the preferred species to plant on riverbanks for landscaping and flood control purposes (Lee, 2004).

The genus of the willow in Latin, Salix, is a combination of the words sal, which means 'nearby,' and lis, which stands for 'water.' The willow is also known to be a spirit that beckons the season of spring, as it is the first tree to find thawing veins of water underground (Lee, 1982). The transformation of the hollow, lifeless body of the winter willow that comes back to life with new sprouts in the spring symbolizes the cycle of life.

The willow has astounding life-sustaining and reproductive qualities, and may be easily reproduced by cutting or layering. It also adjusts exceptionally well to the surrounding environment. The willow that stands on a three-way intersection in the city of Cheon-an is said to have grown from a walking stick made of willow wood that somebody stuck into the ground. Thus, the willow is considered a symbol of prolificacy and life for its vitality and fertility, and large willows are worshiped as religious or sacred trees (Lee, 1982).

In Buddhism, the willow symbolizes the boundless mercy and compassion of the Goddess of Mercy, also known as Avalokiteśvara. Just as the willow branch sways to the slightest wisp of wind, it is thought to symbolize the mercy of the Goddess who responds to the tiniest wish of mankind and heals them with the sweet water of immortality. Just as the branch of a willow moves in whatever direction the wind is blowing, the wishes of mankind are granted, whatever they are. As a tree that grows independently near bodies of water and the first to leaf out in the spring, the willow has come to symbolize water and life. The willow may thus be a representation of the truth that Buddhism seeks to spread. 
Lady Yuhwa, the mythological mother of the founder of the historical kingdom of Goguryeo, is also known as the Lady or Goddess of the Willow Flower. The archetypal symbol of Yuhwa includes the archetypal symbol of a tree that is based on the properties of that tree, which are related to those of the willow (water, spring, feminine image). She is known as the daughter of Habaek, a god of water. Her holy traits, including the archetypal symbols of the tree such as regeneration and vitality, as well as her maternal personalities, such as fertility, prolificacy and abundance, were reinforced in the myth (Choi, 2008). The tree as a symbol of maternity contains the symbols of all features of death and life, including the symbol of the Tree of Life, and the symbol of the cross that symbolizes death and resurrection (Lee, 1995). Thus, the character of Yuhwa represents qualities of the willow, and illustrates the feminine, or maternal, principle of creation in which yin as opposed to yang controls water to bring prosperity (Lee, 2004).

All trees, including the willow, use their roots to absorb water and nutrients from under the ground while receiving light and air from above the ground to accomplish comprehensive growth. In Marion Woodman's book, The Ravaged Bridegroom - Masculinity in Women, a female client goes through a process of healing by integrating the earths and the skies, the consciousness and unconsciousness, and the spirit and matter through the symbol of a tree, which is in this case the willow (Woodman, 1990). A tree may also symbolize the ego-Self axis. The ego-Self axis enables communication between the Self and the ego (Kast, 1994). The separation of the Self and the ego, the formation of the axis, and communication through that axis allows one to retrieve passion and the impulse for life from the Self (Edinger, 1972).

In Woodman's book, The Ravaged Bridegroom - Masculinity in Women (Woodman, 1990), a female client suffering from an addiction rooted in her animus, which is not in separation with the Self, goes through a healing process that involves thinking about the image of the willow. To break away from her addiction and regain her senses, she had to understand the magical illusion that turns water into a milk of paradise. Once the client regained her senses, she realized that the milk is nothing more than plain water (Woodman, 1990). The client healed her animus of addiction, and on the crossroad of life and death learned what her 
Journal of Symbols \& Sandplay Therapy, Vol.10 No.1.

body wanted, which is in fact what her soul desired. The client came to understand the principles of the universe and her personal experiences in association with the image of a tree, and through imagination and association with the willow, integrated the spirit and matter (Lee, 2004).

As a Jungian analyst, Woodman carried out several studies on female issues such as addiction and eating disorders. She also took a neurobiological approach to understand the relationship between the psyche and soma. In her speech "Women, Power, and Soul," Woodman accurately pointed out the state of the modern society in which there is a lack of the feminine principle. "What we need now is the feminine principle. We are living in times in which receptive attitudes, the soul, and feelings are important. Femininity is the energy that supports the existence of human beings, that is, our deep and slow internal world." ("Why She Tried to Touch Me." Channel Yes. Modified on February 3, 2015. Visited on November 5, 2017. http://m.ch.yes24.com/Article/View/16861). The key word in Woodman's speech is not femininity but feminine energy. Here, the willow becomes a symbol of feminine energy that instills vitality into the body. By projecting the image of the willow to her body, the client was reborn with feminine vitality. This study looks into this process of healing addictions, and seeks to understand the symbolism of the willow in terms of its religious, folkloric, and mythological aspects.

Modern day human beings are distant from their body, instincts and senses, which makes it difficult for them to listen to their internal voices. This physical and psychological state may prevent the achievement of a union or balance between the psyche and the body, or consciousness and unconsciousness (Jung, 1984/2001). When this state continues, energy in the body and psyche may be obstructed, leading to somatic symptoms. It has been found in many clients that dreams, imagination, and sandplay therapy allow emotions to come to life (Jang, 2017). Perhaps this is the divine moment that Woodman hopes people today who need healing encounter, in which they enter a truly communicative relationship with their inner selves through relationship-based feminine principles. With that, this study embarks on its journey by first taking a look at Woodman's client and how the willow was used to symbolize the feminine principle. 


\section{П. Qualities of the willow}

\section{A. Ecological characteristics of the willow}

Willows are deciduous trees that make up the Salicaceae family. They are tall, growing up to 20 meters. The flowers bloom in April and the fruit ripe in May. They grow in all places across Korea, and are often found near streams. They are also found across Manchuria and Japan. The scientific name for these willows is Salix koreensis ANDRESS. The genus is Salix, which in Latin is a combination of the words sal, meaning 'nearby,' and lis, meaning 'water,' fit for a tree that loves moisture. Willows have dark brown bark and yellow-green branches that break away easily from the trunk. Therefore, it is always wise to be cautious when climbing a willow tree, even when stepping on a large branch (Lee, "The Willow." Encyclopedia of Korean Culture. Modified in 1995. Visited on March 2, 2018. http://encykorea.aks.ac.kr).

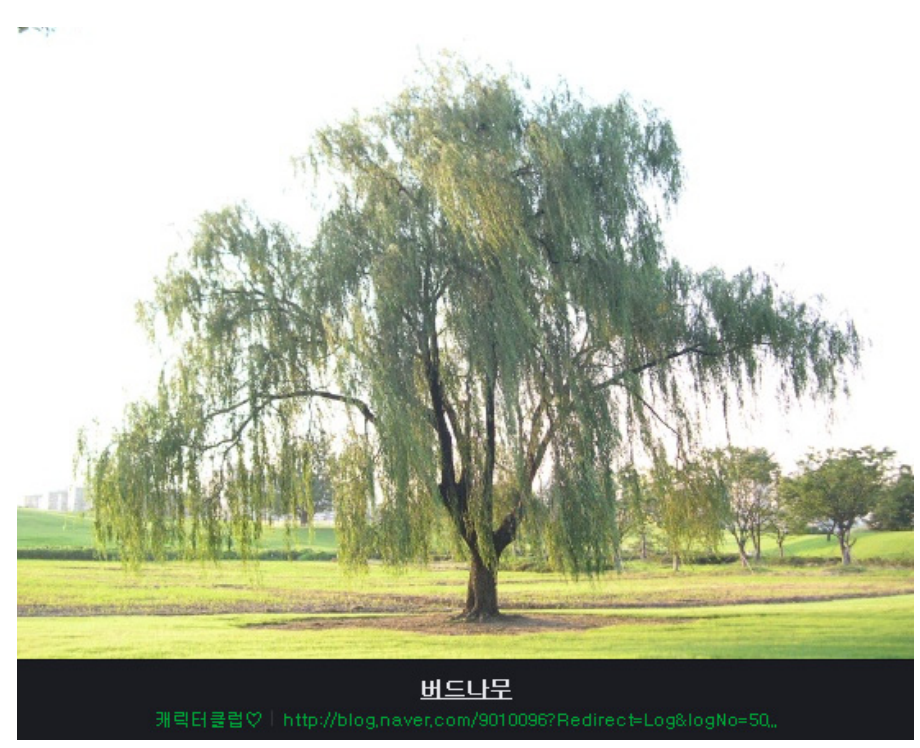

Image 1. The Willow

Source: "The Willow." Character Club. Modified on July 8, 2016. Visited on November 5, 2017. http://blog.navercom/9010096? Redirect $=\log \& \log \mathrm{No}_{0}=50$. 
Journal of Symbols \& Sandplay Therapy, Vol.10 No.1.

The leaves are linear-lanceolate or similar, and are narrow on both ends. The upper ends are long and acute and are serrated on the edges. The surface is smooth. Some trichomes are found on the main backside vein, but they fall out quickly. The winter buds have short trichomes. The male and female flowers grow on separate trees but are sometimes found growing together on a single tree. The spike of the male flower is about one or two centimeters long and trichomes are found on the axis of the flower. The oval bract is covered with silk-like trichomes. There are two stamens for each flower. There are also two nectaries and the filament has trichomes underneath (Lee, 1982).

A rotten willow trunk contains water, which makes it sparkle when it is dark. People living in the countryside used to think that the light is coming from a goblin's fire and were terrified. Most stories of goblin encounters therefore come from wet woods with a dense willow population. This is just another example of how closely the willow is connected to water (Lee, 1982). As such, the branches of a willow are filled with the vitality of water, making them delicate and soft. In Korea, the willow is called 'buh-deul-na-moo', which sounds similar to 'bu-deul bu-deul', or 'soft.' As such, it is said that the name of the tree is derived from the softness of its branches (Lee, "The Willow." Encyclopedia of Korean Culture. Modified in 1995. Visited on March 2, 2018. http://encykorea.aks.ac.kr).

\section{B. Uses of the willow}

\section{1) Praying to the heavens for rain}

In agrarian societies, precipitation is a critical condition for the year's harvest. Rain is something given by nature and cannot be controlled by mankind. During the farming seasons of spring and summer, a period of wind normally precedes rainfall. People could tell that wind was coming when the leaves and branches of large willow trees started to shuffle. The willow, whose leaves and branches sway to the slightest breeze, may thus have been the sensible choice of a tree to be presented in rituals that were held to ask for rain. The willow is also an aquatic tree that symbolizes spring and the vitality of all living things, which again makes it a suitable choice for these rituals. Fung-shui experts may have used the willow branch for similar 
reasons when looking for the right place to dig wells. As such, the willow has always been a part of traditional Korean culture, often being used as a sacred object that was presented to the heavens (Lee, 2004). As the first tree to bear new life after the long, icy winter with the energy of water and wind, the willow may have been in fact be the most suitable choice.

\section{2) Water purification and flood control}

Willows were often planted near wells. Not only do they create wide shades over the well, but the proliferous roots of the willow help purify the water by absorbing the nitric and phosphoric acids.

An example of the willow being used for flood control can be found in the story of the Hwaseong Fortress, which was constructed in the city of Suwon during the reign of King Jeongjo. At the time, King Jeongjo ordered willows to be planted on the bank of the Suwoncheon River for landscaping and flood control purposes. Suwon is thus referred to as the 'Willow City,' and the Suwoncheon River the 'Willow River.' King Jeongjo set up farming land by creating waterways and reservoirs, and had willows planted around them. The massive amount of fine roots growing underneath the willow are known to be particularly effective in flood prevention and recovery (Lee, "The Willow." Encyclopedia of Korean Culture. Modified in 1995. Visited on March 2, 2018. http://encykorea.aks.ac.kr).

One of the pavilions in the Hwaseong Fortress is called the Banghwasuryujeong, which stands for 'running after flowers and willow trees.' It is a beautiful facility that allows the Fortress to blend into the surrounding view while still fulfilling its military purpose of surveillance and command. The unique roof of the pavilion goes well with the willows that stand on the edges of a nearby pond, creating a harmonic picture altogether ("Yangpyeong Dumulmeori, into the Story." Mountain Story Blog. Modified on June 12, 2018. Visited on September 11, 2018. https://blog.naver.com/singleway/221297493561). Harmonization was in fact one of the key elements that made up the governing ideologies of Kings Yeongjo and Jeongjo, which is believed to be the reason behind the prosperity enjoyed during their reign. 
Journal of Symbols \& Sandplay Therapy, Vol.10 No.1.

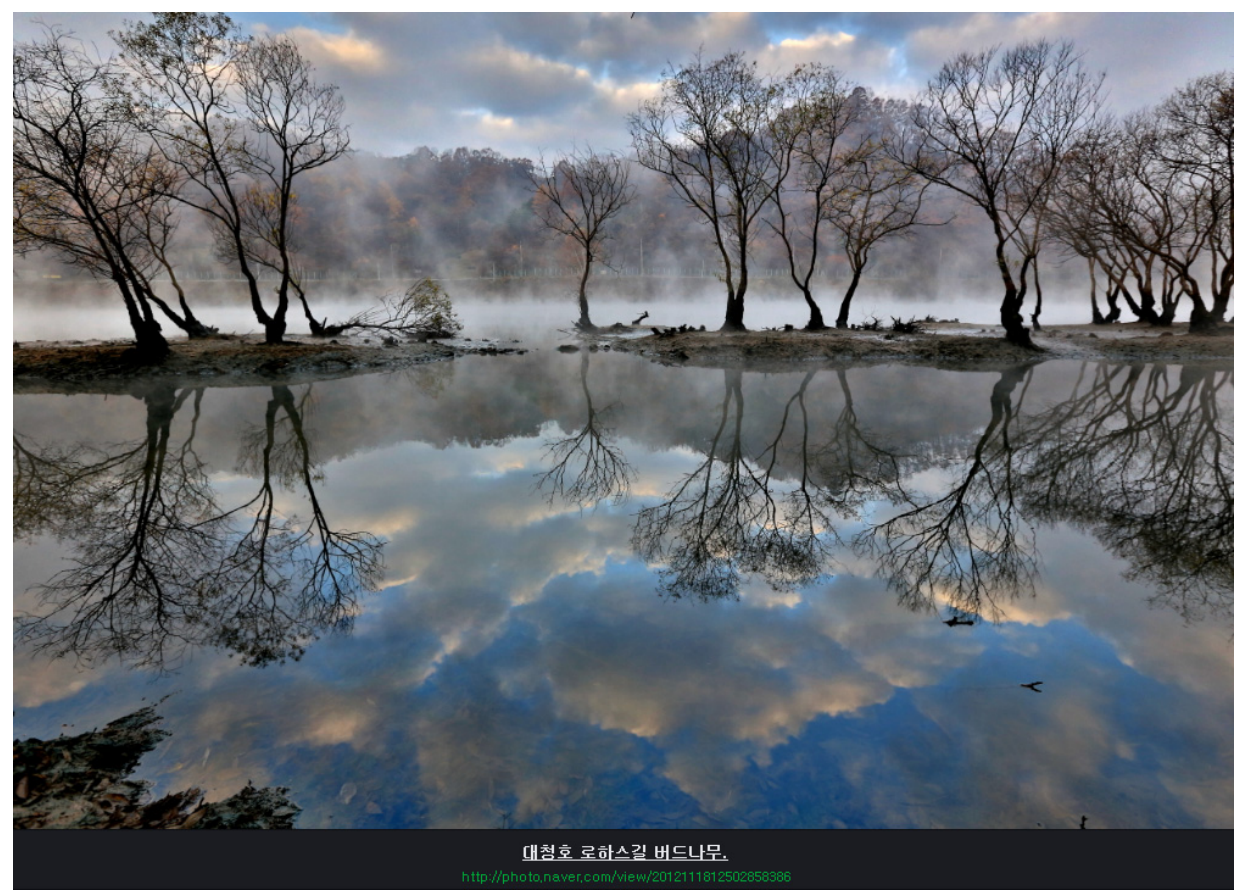

Image 2. Willows on the Lohas Walkway of the Daecheongho Lake

Source: "Willows on the Lohas Walkway of the Daecheongho Lake."

Modified on February 12, 2016. Visited on November 10, 2017.

http://photo.naver.com/view/2012000812502858386

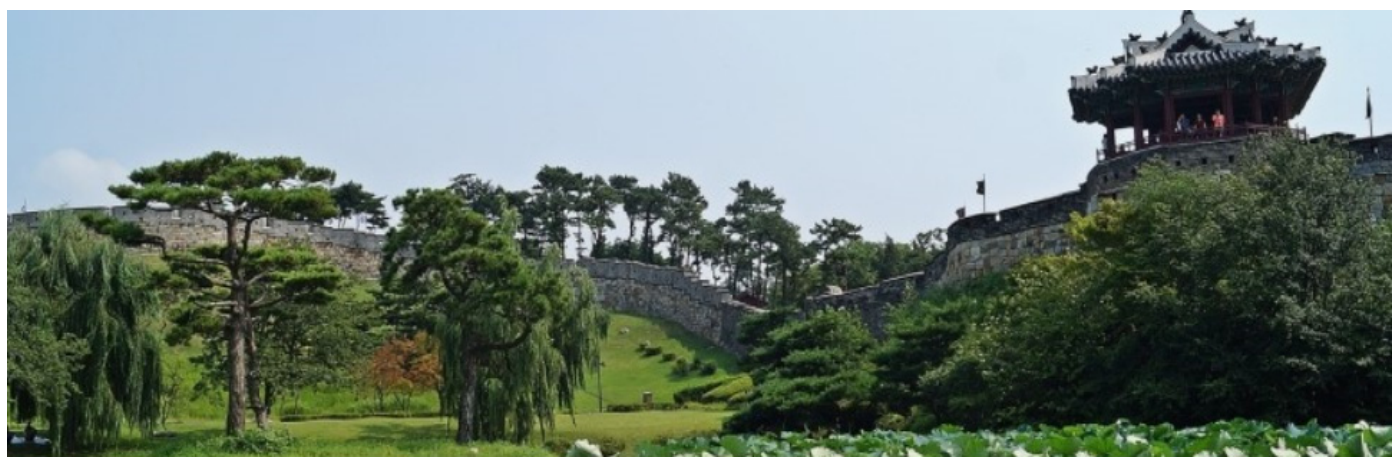

Image 3. Banghwasuryujeong of the Hwaseong Fortress

Source: "Banghwasuryujeong of the Hwaseong Fortress."

Modified on June 20, 2014. Visited on November 3, 2017.

http://blog.naver.com/kairai?Redirect-ghktjd 


\section{3) Folk remedies and other medical uses}

The willow is known to have been used in folk medicine to treat lacquer poisoning, high fever, hepatitis, high blood pressure, kidney disease, toothache, boils, and menopause symptoms. The branches and leaves of the willow were collected and let dry under the sun during the spring and summer. For lacquer poisoning, high fever, hepatitis, high blood pressure, kidney disease, or bronchitis, drinking tea made by boiling 20 grams of dried willow in 700 milliliters of water was helpful. Toothaches or boils could also be relieved by dabbing water boiled with dried willow. The willow flower was also dried under the sun and used to treat menopause symptoms and toothaches. The bark of the willow was used to promote urination and to make ointment (Lee, 1982).

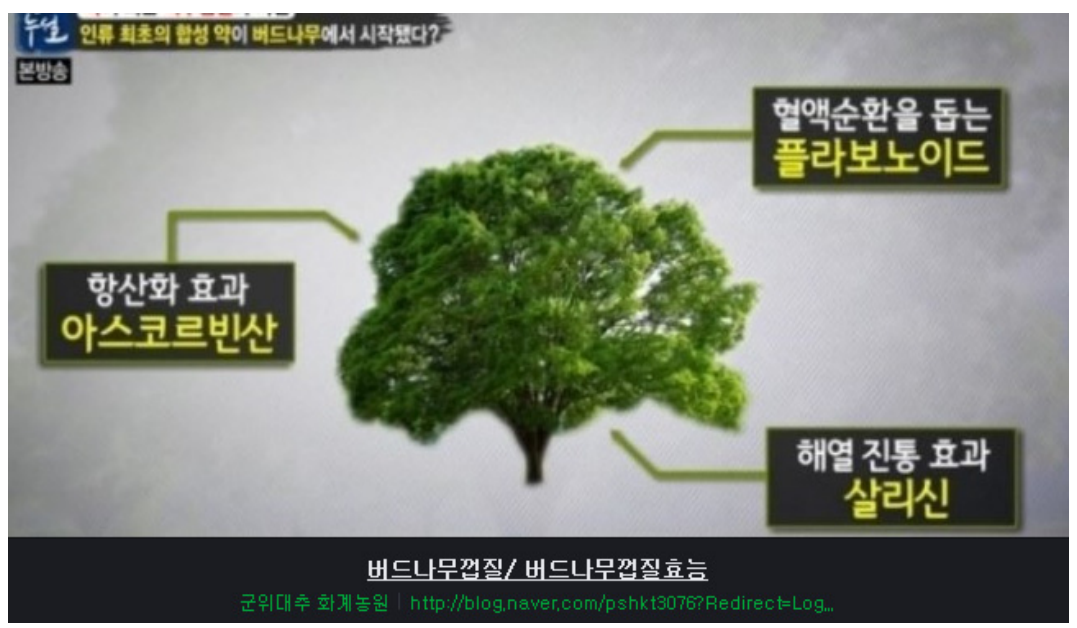

Image 4. Uses of the Willow Bark

Source: "Uses of the Willow Bark." Gunwi JuJube Hwagye Farm.

Modified on April 5, 2014. Visited on October 20, 2017.

http://blog.naver.com/pshkt3076? Redirect $=$ Log.

Aspirin, which is a common medicine for fever and pain relief, is also known to include an ingredient that has been extracted from the root of the willow. Recently, its uses have expanded from the treatment of fever and pain to preventing cardiovascular diseases. 


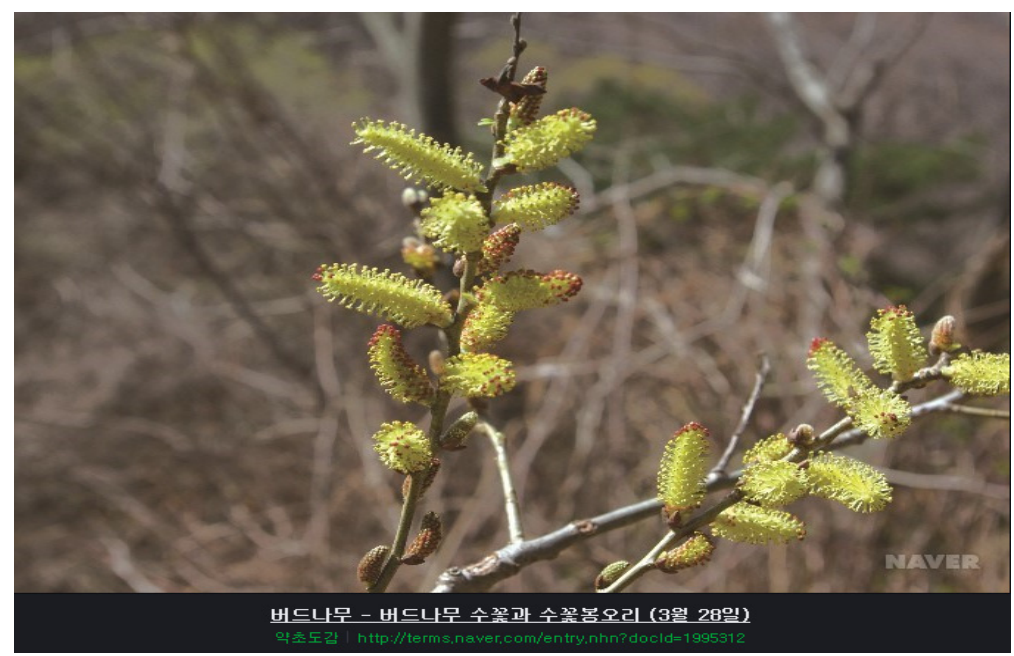

Image 5. The Male Flower and Flower Bud of the Willow

Source: "The Male Flower and Flower Bud of the Willow." The Medicinal Herb Guide. Modified on March 28, 2000. Visited on October 20, 2017. http://terms.naver.com/entry.nhn?dicId=1995312.

\section{Woodman's symbolism of the willow}

Reading Woodman's book, The Ravaged Bridegroom - Masculinity in Women (Woodman, 1990), was enough to be captivated by the female Jungian analyst Marion Woodman. Woodman carried out in-depth clinical and theoretical studies on women's addictions. She also demonstrated much passion in her writings and lectures on the principles of femininity. The researcher had the chance to translate part of Woodman's book and present it during class. It was a part discussing the story of a female client who suffered from a form of addiction and eating disorders. At the crossroad of life and death, the client embarked on the journey of healing by visualizing her body with the symbol of the willow, with the help of Woodman's analysis.

The researcher went out to look for willows, but soon realized that it was hard to find one in the city. Willows would probably have been more common in our lives in the past than they are today. Then one day in early spring, the researcher happened to drive past a 
willow tree. Other trees on the road were completely inanimate, but the willow had delicate leaves that moved along with the gentle spring breeze. The movement kept the researcher glued to the spot. The breeze and the delicate leaves of the willow seemed to be symbolically representing the relationship between a client and therapist. Swaying in the breeze, the willow was demonstrating its very existence with its entire body. It was also as if the leaves on the branches were responding to the fine vibrations of the world. The impressions of that short moment led the researcher to begin a journey of exploring the symbolism of the willow.

Now I do yoga regularly, taking images into into my body. I concentrate on a willow taking root. I am trying. As I breathe into my spine I use the willow to breathe life in and I'm surprised and thrilled to feel my body take it in and melt. Then I feel connected to the earth and thankful to be alive. I don't know if I would have understood all this had I not crashed into the wall (Woodman, 1990, p. 61, line 7- line 13).

Here, the female client visualizes the willow as an image inside herself and forms a relationship with Mother Earth. From there, she gains new life. She is connecting herself with Mother Earth, rooting herself deeply and breathing in vitality.

Neumann (1974/2007) said that the great Mother Earth, which gives life to all living things, is the mother of all plants, and that the tree is at the center of what plants symbolize. The tree bears fruit and is a safe haven for forest creatures. It symbolizes femininity. To the client, the willow is a place where the soul rests, and the home of the spirit of the tree. Within maternity we meet with the archetypal mother, or the Self, and start a journey of separation from the personal mother. In the process we achieve ego development (Lee, 2015). The client was deprived of safe maternity and was overwhelmed by the mother complex. Going beyond the perception that she simply could not receive help, she believed she was doing 'something bad' or committing a 'sin' (Kast, 2010).

Every morsel I eat and every walk I take I must be aware of. I am learning that by allowing my body to soften and take in, my body is fed. There are energies within that do feed me. Learning that takes all my strength because for me to soften feels like death itself. I keep working with the energy of the willow. Bringing that life-giving energy into by body, I am nourished. The receptivity melts the compulsion (Woodman, 1990, p. 62, line 10-line 16). 
Journal of Symbols \& Sandplay Therapy, Vol.10 No.1.

Here, the client becomes aware of the nourishment her body is receiving and that her body is consuming it. A women's body embodies the pivotal symbolism of a container. The bodily experience of being a container is universal. The container, which is the body, holds and digests food and excretes the waste through metabolic processes (Neumann, 1974/2007). The client, who sabotaged her body with the eating disorder, received the vitality of the willow and started to look after herself. She went back as a fetus inside the body of her mother and recovered the origin of creation.

This is the story of the female client introduced in Woodman's book, The Ravaged Bridegroom - Masculinity in Woman (Woodman, 1990). Right after she was born, she was mistakenly swapped with another baby by the hospital staff and was therefore deprived of the initial bond with her biological mother. Although she later reunited with her biological mother, the mother considered her only as the haunting presence of her 'first' child, whom she had to send away. The client started to perceive herself as a ghost, or something different from her true self. She submitted to the commands of her animus and started to dominate her body and psyche by setting perfectionist standards (Woodman, 1990).

The Self is the entirety of all psychological events that occur in the consciousness and unconsciousness of a person. It is an 'all-in-one character.' When consciousness and unconsciousness start to connect after breaking away from the spell of the animus, the Self moves toward unity and wholeness (Jung, 1984/2004). When captured by the animus, a woman does not understand that her judgement is completely assimilated with unconscious, negative opinions. Therefore, it is imperative that the woman understands that she has been captured by the animus and move on to achieve self-realization. This is how the inner and conscious worlds sustain a relationship (Lee, 2002). The animus contains elements of oppressed personal unconsciousness, but the roots remain in the archetypal conditions of humanity (Lee, 2001).

Woodman (1990) has said that a child who is deprived of adequate physical touch with the mother fails to develop a sense of bonding that is needed to trust one's instincts. The child is unable to breathe in the arms of the mother and consequently cannot breathe on her own. The client, who was unable to bond with her mother, unconsciously rejected her own 
body. The body forgot how to relax and move with its own energy. She moved from false control to rigid control to loss of control. The pattern manifested in her eating addiction, her shopping addiction, and her ways of spending time and money. In almost every area, her life fluctuated between feast and famine (Woodman, 1990).

What distressed her the most was alternately gaining and losing thirty-five pounds each year, and the diabetic complications that came from the eating disorder. One weekend she went into a coma and woke up at the hospital. Recalling the shock and the consequent changes in her life, she wrote, "I had to learn about my soul and what my soul needed just as I was learning about my body and what my body needed" (Woodman, 1990, p. 59, line 2-line 8).

It was on this crossroad of life and death that she started to follow a path of renewed healing by projecting the image of the willow on her body.

Her body relaxes, opens to light, and feels God within her. She loves and knows she is loved. She enters into a relationship with the image of the willow in her body and takes the energy out of her complex and pulls it toward her conscious ego. The dragon mother is sacrificed (Woodman, 1990, p.63, line 18-line 22).

The ego is at the center of consciousness and is acknowledged. By becoming aware of and overcoming the ego complex, one can prevent the contents of unconsciousness sinking even deeply into the dark (von Franz, 1981). The critical role of the ego is to have the person form relationships with and adjust to the outer world and also with the inner world, or unconsciousness (Lee, 2002). No longer the enemy of the ego, it becomes Sophia, the wisdom and love that are the life force of her being (Jung, 1984/2002). Sophia's consistent mercy of healing dispelled magic and opened her to reality, physically and psychically. Abandonment by the physical mother left psychic space for the entry of the archetypal mother. Trusting her, the addict experienced grace that heals the betrayal of trust (Woodman, 1990). As the client struggled to listen to her inner femininity and played with the images that arose in her body, she came into contact her own inner healer. The feminine energy of healing of the willow that contains vitality connected the abandoned body to the soul.

The case introduced by Woodman, who carried out several studies on female addiction 
Journal of Symbols \& Sandplay Therapy, Vol.10 No.1.

and food disorders, demonstrates the process of healing the animus of addiction by instilling the innate vitality of femininity to the body. By projecting the image of the willow to her body, the client came to life again with feminine vitality. This study looks into the archetypal elements of the vitality of the willow that connects with its femininity and how they are symbolized in Buddhism and the mythological and folk culture of Korea.

An archetype lasts for thousands of years but constantly requires new interpretations. Archetypes are firm elements that make up the unconsciousness but continuously change in shape. It is almost impossible to remove an individual archetype from bodies of meaning that are alive in the heart and soul. Even though the bodies are entangled with one another, the archetypes form unity, which is intuitively understood (Jung, 1984/2002, p.272, line 1-line5).

Another significance of this study is that it has allowed reflection on what Jung discussed as the transcendental and ancient characteristics of collective unconsciousness, which brings together cultural and religious differences of the West and East.

\section{A. The willow in Buddhism as a symbol of healing}

The client introduced by Woodman healed her animus of addiction that conquered her abandoned body with the unwavering mercy of Sophia. As the fourth stage of eroticism as discussed by Jung, Sophia represents eternal femininity and is the goddess of wisdom of alchemy (Jung, 1985/2004).

As men attain wisdom from the religious sublimation of physical and romantic craving for love into merciful love through the division and integration of the anima, women gain proactive behavior and materialize the specific meaning of words to empower them and intermediate wisdom (Lee, 2001, p.102, line 1-line 4).

This implies that in order to have the anima and animus move on to individuation rather than remain in an inferior state of the inner personality, archetypal aspects must be recognized and that effort is needed to become conscious of the personal aspects. The pain of addiction guided the client to discover inner wisdom, and by becoming conscious of the light inside her body she was led to psychically perceive the unwavering mercy of Sophia.

Jung has said that just as Buddha is the symbol of wholeness and the self-archetype, 
the Goddess of Mercy may also be perceived as a symbol of internal character that leads toward wholeness, and also as symbol of the anima or at times the animus. Perhaps the Goddess of Mercy represents the highest level of anima, also known as Sophia, which is at a level higher than the Virgin Mary (Lee, 2001).

The Goddess of Mercy presents herself in thirty-three different tangible forms. Of them, the most common form is the YangLiu Guanyin, in which the Goddess is holding a willow branch with her right hand and her left hand is placed on her left chest. The term YangLiu stands for willow tree. In Korea, the YangLiu Guanyin is most commonly worshipped form of the Goddess of Mercy. Just as the willow branch sways to the slightest breeze, the YangLiu Guanyin is believed to provide delicate care for mankind and fulfill their wishes (Lee, 2004).

The YangLiu Guanyin normally stands against a huge circular nimbus on a pedestal shaped like a lotus floating on the ocean. Shancai (also known as Sudhana) is always present at her knees, listening to her teachings. The people mistakenly took this as an implication that the YangLiu Guanyin is a goddess who blesses couples with a son, so many families went to the YangLiu Guanyin to ask for one. Sometimes she is portrayed as sitting on a rock near a stream of water, with vases of willow branches on either side (Chung, "The Goddess of Mercy holding a Willow Branch - YangLiu Guanyin.” Beopbo News. Modified on July 12, 2017. Visited on October 30, 2017. http://www.beopbo.com).

In Buddhism, a willow branch symbolizes the boundless mercy and compassion of the Goddess of Mercy. It is believed that the Goddess uses the willow branch to sprinkle the sweet water of immortality stored inside her jar to heal mankind. Thus, the willow is used to fulfill the wish of the Goddess of Mercy to save this world by spreading her mercy widely across the suffering people. As a tree that grows on its own near bodies of water and the first to leaf out in the spring, the willow has come to symbolize water and life. It may thus be a representation of the act of spreading the truth of Buddhism (Lee, 2004). The client may have needed the mercy of the Goddess and the symbolism of the willow to heal and transform the compulsive impulses that assault her body into an innate energy that helps rescue herself with the feminine energy of water and vitality. 
Journal of Symbols \& Sandplay Therapy, Vol.10 No.1.

All statues of Buddhist saints are known to be male, with the exception of the Goddess of Mercy. However, the Goddess of Mercy also was originally portrayed as a male god. Thus she is perceived not only as a figure of a common gender but one that transcends the two different genders. The term Guanyin means 'perceiving the sounds of mankind.' The Goddess lifted herself out of karma into a state of nirvana and offers mercy to those who seek to break out of the shackles of pain (Lee, 2001). Woodman's client strived to come close to the image of the willow forming inside her body, and through the process became conscious of the femininity within herself. She met with the internal healer, who is the Goddess of Mercy. Her now conscious body was able to truly accept the god that she had struggled so hard to unilaterally connect with, which is the Self. The archetypes formed the unconscious images within her, and as the deep foundation of character, wholeness integrated the consciousness and unconsciousness and transcended ego (Woodman, 1990).

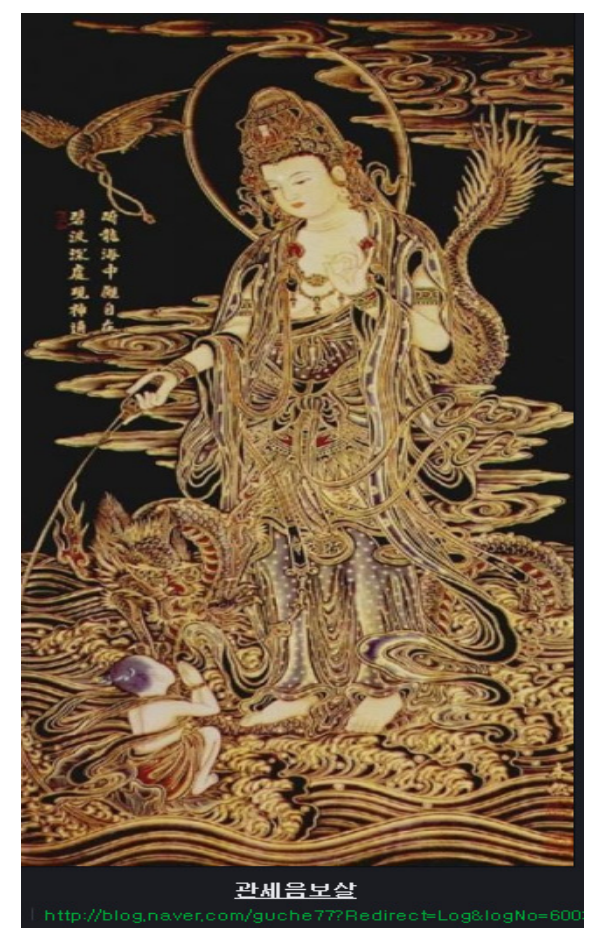

Image 6. Goddess of Mercy

Source: "Goddess of Mercy." Beopbo News. Modified on July 12, 2017. Visited on October 30, 2017.

http://www.beopbo.com. 


\section{B. Symbolism of Lady Yuhwa in the foundation myth of Goguryeo}

In her analysis, Woodman (1990) stated that one of the most challenging tasks was to find a loving relationship between the client's spirit, which has left the body, and her body, which was in a state of unconsciousness. The client was unable to form secure attachment with her mother early in life. Her animus recognized what was happening as her body was trying to open up to femininity, and asserted even more pressure (Woodman, 1990). As her body was controlled with force, she experienced convulsions and distortions on the left side of her body. Her body continued to be sacrificed as she was trying to analyze everything.

No matter how hard I tried to control my body, I realized that my pancreas was not functioning well. As I became more anxious, it became even more difficult to control the blood sugar level. I did everything I can. I took medication, worked out and tried to lose weight obsessively. I had to face the fear inside my body that I was afraid to go near. I had to accept the fact that I have to take in insulin every day. I started to realize how cruel I had been to my own self. Recognizing this was the first step for me to start understanding my fundamental anxieties. I did not receive protection from my internalized mother, and felt as if I was being swallowed by the world (Woodman, 1990, p.65, line 8-line 19).

The addictions the client had with food might have been in fact a representation of her struggle to connect with god, or the source of internal energy. She learned that this can be realized only by the love of the mother archetype, and was at last able to connect her soul to her body. An example of the feminine mother archetype connecting the soul to the body is also found in the foundation myth of Goguryeo.

The willow tree serves as the root of feminine vitality in shamanistic cultures and foundation myths across East Asia. In particular, the symbolism of the willow is closely connected to the mother of the mythical founder of Goguryeo, Yuhwa (Lee, 2004). The symbolism of the willow that Yuhwa holds in the foundation myth played an important role in sanctifying and securing the legitimacy of the king. An interesting aspect is that the willow is not portrayed as an actual willow in the foundation myth. It is portrayed in the form of a human character who takes on the same symbolic characteristics of a willow, namely femininity, holiness and mediation. Most notably, Yuhwa adds legitimacy and sacredness to the throne. 
Journal of Symbols \& Sandplay Therapy, Vol.10 No.1.

Yuhwa was the wise wife who prepared the groundwork for the future king. In fact, not only in the stories of ancient kingdoms but also in those of feudal societies, being wedded to a willow maiden was one of the key factors in maintaining authority (Lee, 2004). The story of the client in Woodman's book also implies that an archetypal integration with the willow maiden is an essential condition to connect consciousness to the unconsciousness, and the spirit to the body.

The son of heaven, Hae Mosu, sought to marry Yuhwa to give birth to a son who will succeed him. He chose Yuhwa for her qualities of prolificacy and abundance. Laying his eyes on Yuhwa for the first time as she was taking a bath with her sister in a pond, King Hae Mosu said, "If I take that woman to be my wife, I will certainly be able to bear offspring." Hae Mosu had perceived the quality of abundance that the daughter of the god of water held. The name 'Yuhwa' itself suggests that she is the sacred manifestation of the willow, a tree that proliferates near water. But for Hae Mosu to marry Yuhwa, he had to receive prior permission from her father, Habaek. When this did not happen, Habaek challenged Hae Mosu to a duel of metamorphosis and confirmed that he is the son of heaven. But Hae Mosu abandoned Yuhwa and went back to heaven on his own. Habaek abandoned Yuhwa for the failed marriage. With no one having their desires fulfilled, the story continues, awaiting a true, sacred marriage.

Yuhwa, who was exiled to the riverside, was later confined in an annexed building of King Geumwa's palace. One day, she was exposed to sunlight coming after her, which symbolizes Hae Mosu. She conceived and gave birth to an egg. The egg hatched and Jumong, who later became king, was born. From an early age Jumong had bright eyes and was remarkably talented in archery. As his exceptional powers became increasingly evident, the crown prince of Buyeo became jealous. Jumong eventually left Buyeo and decided to establish a kingdom. Yuhwa helped out by recruiting skillful archers, finding strong horses and procuring seeds for farming. Jumong may not have been able to leave Buyeo nor establish a kingdom if it were not for his mother's help.

The people under Jumong were horseback-riding nomads who made a living by farming and hunting. As they moved into the Yalu River area, they converged with the 
indigenous residents, who had authority over water and are thus interpreted as Habaek. As the daughter of Habaek, Yuhwa was associated with the goddess of crops in the agricultural society. She was worshipped as the goddess of abundance in Goguryeo, and later became the subject of religious faith.

The image of Yuhwa reuniting with Hae Mosu in the form of sunlight is in a way similar to how a plant grows and flourishes. The process of Yuhwa conceiving an egg with the sun shining down on her is symbolic of the process that plants go through as they grow and bear fruit. This vitality that leads to abundance is also a feature of the goddess of crops. The abandonment and confinement of Yuhwa are symbolic of hibernation, or temporary death. Just as Persephone in Greek mythology implies the cycle of nature by going back and forth from the underground to the surface of the earth, Yuhwa also conformed to the principles of life. Even after a sexual bond was made, she had to go through a particular process to become the mother of the heir: she was abandoned on the riverside, had her lips cut three times to regain speech and absorbed sunlight to conceive the child. These preconditions - water, severance and sunlight - are in fact the very same elements that a willow needs to grow and propagate. The story of Yuhwa may thus be a personified, narrative description of the mythical processes that are associated with the willow goddess (Lee, 2004, pp.36-37).

Here, the image of a shaman is also delivered. Shamans are the mediators of sacred trees, gods and human beings, and they were the commanders in the era of theocracy who communicated with the gods. The story of Yuhwa follows stories of willow godmothers in Manchurian mythology, or the mother of the Great Shaman. As the mother of Goguryeo, Yuhwa embodied the three qualities that the willow godmothers of the Ural-Altai region had: the feminine symbolism of yin, water, and the willow. She secured the basic necessities for an agricultural society by procuring seeds for planting and was called a godmother in the times of Jumong. She was worshipped as a national goddess up to the Goryeo dynasty. In the foundation myths of the kingdom of Goguryeo, Yuhwa is illustrated as a god-like figure who walks together with mankind and actively pursues prosperity of the people. The image of a feminine character with qualities of the willow, such as viability, power of healing and reproduction, was imprinted on the mother of the founder of the ancient kingdom. The union 
Journal of Symbols \& Sandplay Therapy, Vol.10 No.1.

of a man and wife that leads to the birth of the national progenitor must be a cosmological union. Both the vertical inside - the sky - and the horizontal outside - the water system must be present for the king to gain legitimate authority (Noh, 1995, p.129, line 7-line 17).

As such, the history of an ancient nation must be warranted by the transcending qualities of the founder, or the engagement of a transcending being. To gain legitimacy, the sovereign ruler of Korea had to inherit not only the bloodline of a male god from the heavens, but also the bloodline of a mother from another world who came into being by water. Yuhwa was the intermediary between the heavenly Hae Mosu and the earthly Jumong. Her reunion with Hae Mosu in the form of sunlight implies the birth of consciousness. An interaction with sunlight materialized into an egg, which symbolizes growth and fruit-bearing.

In her book, Woodman deals with the conflicting powers of a tyrant-like body and a tyrant-like spirit. The more the client makes conscious attempts to solve the conflict, the more it moves away from unconsciousness. This goes in line with Jung's argument that when the psychic energy separates from the unconsciousness, the archetype of the animus is activated (Lee, 2001). When a woman fails to recognize the man living in her unconsciousness - the animus - she ends up being consumed by it. Masculinity overshadows the woman and femininity is pushed away from consciousness, which is now dominated by the animus (Lee, 2001). Once her animus, which tries to shift to a life of experience, becomes conscious, it functions as the dragon slayer that is separated from the instinct. She gives time to form a relationship with the internal animus and learns how to distinguish and respect the areas of instinct.

As Yuhwa endured the periods of isolation, pain and abandonment and remained the foundation of the maternal archetype, Woodman's client embarked on the road of consciousness by building on the maternal archetype that embraces the body and spirit that were abandoned and isolated by her biological mother (Neumann, 1973). Yuhwa is a goddess-like figure who is far more involved in the lives of mankind and their pursuit of prosperity than the goddesses of Northeast Asian mythology. The myth of the godmother Yuhwa consolidates the personified female figure of the willow as the archetype of a mother of a national founder, one who embodies the qualities of enduring vitality, healing and prolificacy. The willow has always been 
a close part of the lives of the Korean people and is associated with water, spring, and femininity. The name 'Yuhwa' is in essence an embodiment of the symbolism of the willow (Lee, 2004).

Emma Jung has said that the challenge of modern women is to take the fighter within them down and integrate internal masculine elements into their character (Lee, 2001). Yuhwa and Woodman's client both connected the sprit and body by becoming conscious of and integrating the animus. By doing so, they were able to readily accept isolation and abandonment and rediscover femininity that brings wholeness into life.

\section{Symbolism of the willow in folk culture}

\section{1) Femininity of the willow}

In Korea, the willow has traditionally been compared to the delicate beauty of women. The willow tree is also called "buh-deul," which conveys the image of thin, flexible branches brushing against the slightest breeze. As such, from a very long time ago, the term buh-deul was used to describe feminine beauty ("Tree Stories by Professor Park Sang-jin 94." Yeongnam Daily. Modified on March 5, 2001. Visited on September 29, 2017. http://www.yeongnam.com./renew/common/printPage.jsp.)

The long, soft and glossy hair of women were referred to as 'willow hair' for their similarities with the willow branch, and their eyebrows were also referred to as the "willow eyebrow' or the 'willow leaf eyebrow' for the qualities they share with willow leaves. The following is a line from the poem "Deep Spring" by Ryu Woo-suk of the Tang Dynasty (Lee et al., 2009):

"The eyebrows of a beautiful women are like fresh willow leaves."

The eyes of beautiful women were also compared to baby buds on willow branches and were referred to as the 'willow eye' or the 'willow eyelid.' Weeping willows were also called 'thin willows' for their delicate branches. The fine, tender branches of the weeping willow brought to mind the image of a well-proportioned woman with a thin waist and slender legs. In fact, thin waists were also called 'willow waist.' From the early ages, a thin 
Journal of Symbols \& Sandplay Therapy, Vol.10 No.1.

waist was one of the first conditions that had to be met in order to be considered beautiful (Lee, 2004). The weeping willow with its graceful figure made up of fine, drooping branches was one of the favorite subjects for poets. The following is a verse from the poem "Wide Joy" by Tu Fu of the Tang Dynasty (Lee et al., 2009):

"The weeping willow outside the window lightly dancing,

Like the waist of a fifteen-year old maiden."

Jeong Do-jeon also associated the willow to a woman in his poem the "Singing Willow," which he included in his collection of poems, the Sambongjip (Jeong, 1397/2009):

"The willow branch is said to be as thin as a dancing waist,

And the green willow leaves are told to resemble long eyebrows.

Add to that a sweet smile,

You will understand what it means to long for."

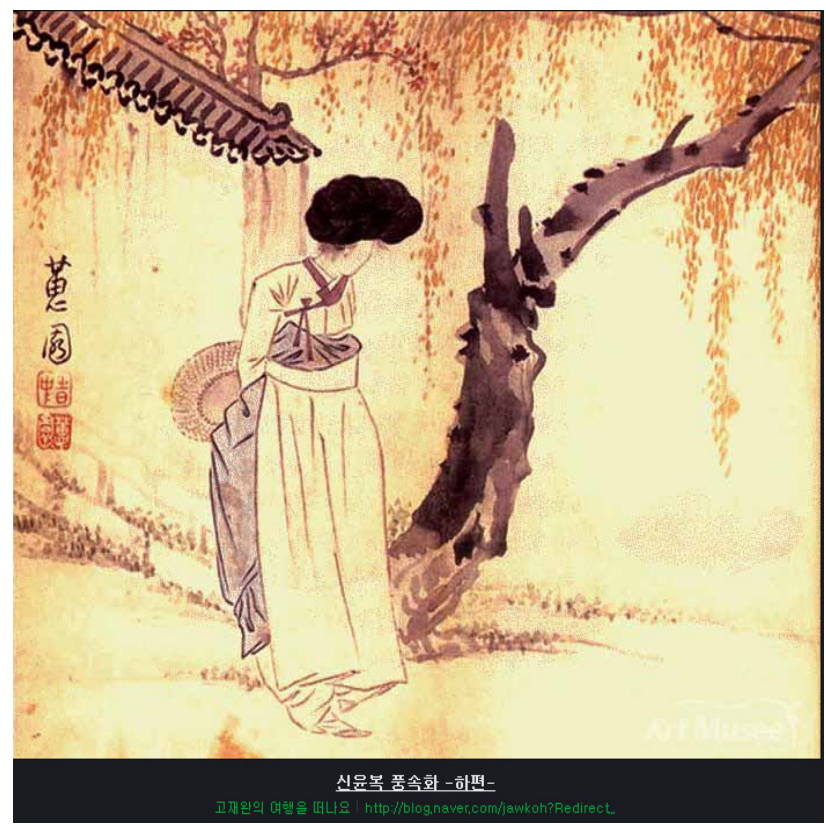

Image 7. Genre Painting by Sin Yun-bok

Source: "Genre Painting by Sin Yun-bok." Ko Jae-hwan, Let's Go on a Trip. Modified on July 2, 2016. Visited on March 5, 2018. http://blog.naver.com/jawoh?Redirect. 
As such, many poets associated the willow with feminine beauty and praised it. Two of the most representative poets of the Tang Dynasty, Han Yu and Bai Juyi, referred to prostitutes who were beautiful as 'willow branch' (Lee et al., 2009). Women whose lives are dependent on men were called 'flower willows.' In various paintings depicting beautiful women, weeping willows are often present in the background (Lee et al., 2012). This may be because the waists of beautiful women were often compared to thin willow branches and also because the weeping willow and slender women fit nicely into a picture together.

Similarly, in the west, the willow is known as a symbol of the moon and femininity (Tresidder, 2000/2007). The term 'willowy' implies gracefulness and slenderness, suggesting that the image of the willow is quite similar in both western and eastern cultures. The soft qualities of the willow are probably what make it comparable to women.

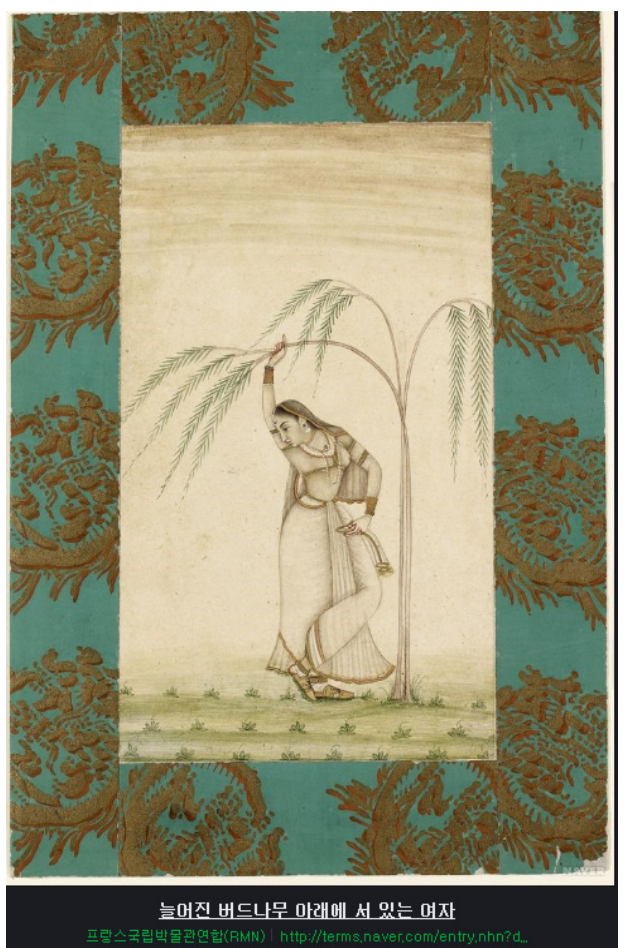

Image 8. Woman Standing under the Willows

Source: "Woman Standing under the Willows." Meeting of National Museums, France (RMN).

Modified on December 1, 2017. Visited on December 11, 2017. http://terms.naver.com/entry.nhn. 
Journal of Symbols \& Sandplay Therapy, Vol.10 No.1.

The willow also symbolizes strong vitality and fertility because of its ability to proliferate and grow wherever water is present. In the Compendium of Materia Medica (Lee, 1590/2018) the willow is described as a tree that can survive standing up or sideways, planted upside-down or upright. As such, the willow is a tree with roots that can find their way into the soil and grow even when planted upside-down.

There are also some old proverbs that compare the willow to women: "The destiny of a women is the same as that of a willow," and "willow trees and women survive even in abandonment" (\#herbs\#willows\#catkins." Sansamnara. Modified on April 23 2017. Visited on December 5, 2017. https://blog.naver.com/yanjinet/ 220990340515). These proverbs compare the tenaciousness of women in the old ages, when they had no choice but to submit and learn how to adapt and survive in the given circumstances, and the vitality of the willow. The women of these times embodied the enduring vitality of the willow, which enabled them to survive in an environment that did not protect them. The myth of the weeping willow that stands on a three-way intersection in the city of Cheon-an that is said to have grown from a walking stick made of willow wood also reflects this trait of the willow (Yoo, 2006). The willow needs only the helping hand of nature to take root. Management of ground conditions, proliferation of the willow and day-to-day care may be left to nature. The conditions for growth are not difficult to meet, and no particular skills are needed. Once planted, a willow can survive in either fertile or barren conditions. As such, the willow symbolizes robust vitality and fertility (Lee, 2004). Thus, the willow was portrayed as a tree that symbolizes femininity in traditional Korean folk culture.

In nature, yang is associated with men and yin is associated with women. The willow carries characteristics of yin. In foundation myths, all kings were married to women who symbolized the willow. Often the king was portrayed as sunlight to depict the fact he is the child of the heavens. Abundant yang can only come into harmony by coming together with yin. Here, the willow is the symbol of fertile femininity and also the symbol of sacredness that connects with the heavens (Lee, 2004, pp 58-59).

On the emotional significance of femininity, by suggesting that "when we think about the circumstances of this age in which the source of power that patriarchy pursues has become 
a subject of parody, what we need now is the feminine principle," Woodman asserted that "we are living in times in which receptive attitudes, the soul, and feelings are important, and femininity strives to find relationships among people" ("Why She Tried to Touch Me."

Channel Yes. Modified on February 3, 2015. Visited on November 5, 2017. http://m.ch.yes24.com/Article/View/16861).

Woodman's client started to perceive feminine energy as she projected the image of the willow on her body in order to connect and integrate the matter and spirit. This feminine energy allowed her to connect with god, and she realized that healing comes from the loving heart of a receptive mother.

My back felt like broken concrete, or bits and pieces of a dried-out clay vessel. Then as I concentrated doing yoga, I could feel water in my body. I was a riverbed. I was flowing with all my little life forms. That made me feel that I had a place in this world, that maybe my life had meaning after all. Images previously have been intuitive flashes, insights in my mind. They weren't able to filter down because there was nothing to go into, like a womb with no blood lining on the walls that the embryo could plant into. Nothing could take form (Woodman, 1990, pp.60-61).

The above is a description by the client of the experience in which flash-like intuition and insights in the mind came to life in her womb, which symbolizes the feminine vessel.

I am the mother of fair love and of fear and of knowledge and of holy hope. I am very beautiful. My body is flawless. I am the mediator that brings all elements together in harmony. I cool what is hot, moisten what is dry, soften what is hard, and vice versa. To the priest I am the commandments, to the prophet the saying, and to the sage advice. I can kill and save. No one can escape my hands (Lee, 2001, p.108, line 5-line 11).

This verse from the mystic classic The Light of Breaking Dawn vividly depicts the image of the anima and femininity. It was cited by von Franz and also by Jung in this book Mysterium Coniunctionis (Jung, 1963/1989). Von Franz explained that at the time of publication, mental culture such as religion and poetry was flourishing, and that the value of the internal world was far more stable than before (Lee, 2001). Woodman's client was healed by going through a process of driving the feminine energy with intuition and insight to the 
Journal of Symbols \& Sandplay Therapy, Vol.10 No.1.

upper-most level of the animus, where wise actions are taken. Perhaps she was following a self-driving guide within her unconsciousness.

\section{2) The messenger of spring}

The willow foretells the coming of spring. When the ground that had been frozen over the winter starts to thaw, the willow sucks up water from underneath the soil and sprouts the first, fresh leaves of spring. The willow thus brings a sense of nostalgia to those who remember it as a tree that ushered spring into their hometowns (Lee, 2004). The pussy willow in particular announces the coming of spring by decorating brooks with colorful flowers bursting from gray cotton ball-like buds. The fluffy winter buds are called catskins. As the first to bloom in early spring, catskins bring joy to many. They signal the beginning of spring, and also the end of spring when the fluffs start to float around aimlessly (Lee, 2004).

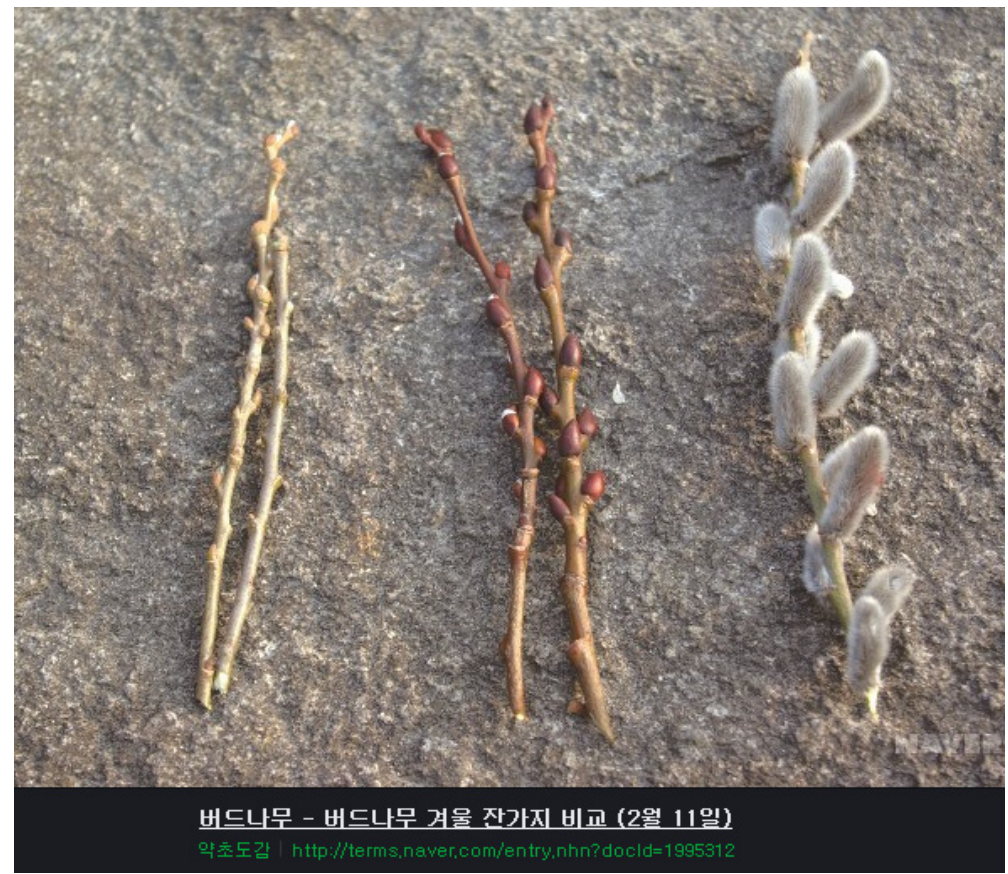

Image 9. Comparison of Winter Willow Twigs

Source: "Comparison of Winter Willow Twigs." The Medicinal Herb Guide. Modified on March 12, 1995. Visited on October 20, 2017.

http://terms.naver.com/entry.nhn?docId=1995312. 
Korean poet Yoo Chi-hwan depicted the way the willow signals the coming of spring in his work as follows (Yoo 1964/1984):

"Although it is not recognizable up-close, from a distance the shade of green is evident. All other trees are still in deep sleep, their eyes closed as if they are blind. Perhaps the thin and delicate branches of the weeping willow are what makes it the first to come to life, recognizing the first signs of spring with delicate sensitivity."

- Yoo Chi-hwan, excerpt from "I am Not Alone"

Here, the poet indirectly suggests that the weeping willow, with its sensitive branches, may be symbolized as the messenger of spring. In her book, Woodman has said that the most difficult task for the client was to recover the relationship between the spirit, which has left the body, and the unconscious body.

"Her body relaxes, opens to light, and feels God within her. She loves and knows she is loved" (Woodman, 1990, p.61).

As the client comes closer to her body and starts to feel with more sensitivity, the spring of consciousness comes to her and through analysis she becomes aware of her desire to be truly loved.

Neumann (1974/2007) said that perceiving the body of a woman as a vessel is the fundamental concept of mythology and symbolism and that the symbolism of a body that contains the psyche is also alive in the modern human being. The universal symbolism of early human history where people form relationships with the world contains the feminine principle. This implies that in the matriarchal stage, femininity dominates masculinity, and that unconsciousness is superior to the ego and consciousness (Neumann, 1974/2007). The sensitivity of the willow to water and wind enables it to signal the coming of spring. The renewed sensitivity of the client's body enabled her to recognize herself as a person who desires to be loved.

\section{3) Symbolism of exorcism}

From the past Korean ancestors interpreted epidemics or unexpected misfortunes as 
Journal of Symbols \& Sandplay Therapy, Vol.10 No.1.

'god's judgement' or the 'descent of god' and held ceremonies to drive away evil spirits. They carried out performances called gut to expel the evil, and through art performances such as the traditional circle dance Gangkang Suwollae, shared with one another hopes for successful exorcism, consoling themselves and the spirits (Jang, 2015).

The willow was perceived to have exorcist powers from the early ages. When someone contracted malaria in the summer, willow leaves in the same number of the patient's age were placed in a paper envelope addressed to the household of a scholar. The envelope was then left on the streets, and whoever picked it up or stepped on it was believed to take the disease in the patient's stead. Another common belief was that if one makes three knots with the branches of a willow early in the morning and pray, the disease will be healed (Lee, 2004).

The Chinese also recognized the mystical traits of the willow and believed in its exorcist powers. The oldest agricultural book in China from the fifth century, Arts of the People, states that placing a willow branch on the door on the morning of the first day of the new year will prevent one hundred different ghosts from entering the house. Similarly, in Korea, there is a belief that hanging a branch from a willow tree over the door in May will help drive away evil spirits (Lee, "The Willow." Encyclopedia of Korean Culture. Modified in 1995. Visited on March 2, 2018. http://encykorea.aks.ac.kr/).

Female exorcists of Jeju Island used willow branches to expel the evil spirits, and farmers made rods out of the willow to use in rituals held to pray to the agricultural gods (Han, 1980). A great willow that stood near the entrance of a village was called the 'guardian' of the village. The willow's resistance to disease and pests, strong vitality, the beauty of its figure, and the large shades it provided it made it a natural fit to serve as the sacred tree of a community (Lim, 1986). The willow's enduring vitality, with its ability to grow even when planted upside-down, may have been another factor.

As such, the willow's sacred ability to expel evil allows it to possess the power of healing, and the power of healing foretells the rebirth of life. The female client introduced by Woodman also came face to face with her negative aspects, or her complexes, and by doing so was able to discover an inner power that enables her to fight. This inner power symbolically revealed the meaning of intuitive healing and exorcism throughout the therapy sessions. That is, 
unconsciousness accomplished exorcism and healing that rationally could not.

Her illness is evoking affirmation of Self in herself. As she leaves behind the tyranny of the old father complex and the inertia of the old mother complex, she is finding the virgin within who decides what is sterling in her silver chalice and she also finds the masculinity strong enough to defend it (Woodman, 1990, p.62, line 17-line21).

\section{Conclusion}

This study looks into the symbolism of the willow and how it is applied to the case of a female client introduced in Woodman's book, The Ravaged Bridegroom - Masculinity in Women (Woodman, 1990), who goes through a process of healing an addiction rooted in her animus that is not in separation with the Self. When we come to an understanding of the principles of the universe and our personal experiences in association with the image of a tree, we are able to integrate the various imaginations and definitions of the tree to the word 'symbol.'

Woodman (1990) associates the symbolism of feminine healing and rebirth with feminine 'energy.' Here, the willow becomes a symbol of feminine energy that instills vitality to the body. By projecting the image of the willow to her body, Woodman's client was reborn with feminine vitality. This study looked into how the symbolism of the willow not only delivered the energy of healing for Woodman's client but also how it is incorporated in religious, folkloric, and mythological aspects.

The mercy of the Goddess of Mercy and the symbolism of the willow may have been what made the transformation to the feminine energy of water and vitality possible. The client heals the animus of addiction with the vitality of the willow that arises from water, and at the crossroad of life and death, learns what the body wants, and that it is in fact what the soul desires. In this process of gaining consciousness, her body comes to truly accept 'god,' or the 'Self,' which she had been struggling to unilaterally connect to. This is made possible by a group of archetypes and indicates a wholeness as the deep foundation of character. It accepts 
Journal of Symbols \& Sandplay Therapy, Vol.10 No.1.

consciousness and unconsciousness and transcends ego.

The challenge of modern women would be to put down the animus fighting from within and integrate the masculine elements of the mind to their character. Yuhwa from mythology and the client from Woodman's book both connected their spirit to the body by becoming conscious of and integrating the animus. Much praise is given to these women who accepted isolation and abandonment and moved on to rediscover femininity that brings wholeness to life.

\section{References}

Roh, S-H (1995). Kingship myths between Korea and Japan. University of Ulsan Press (UUP).

Yoo, S-H (2006). What if this book? The story of trees which are filled with contemplative wisdom. Journal of the Christian Literature Society of Korea, 50(5), 84-89.

Yu, C-H (1964/1984). I'm not lonely. Seoul: Jeongeumsa.

Lee, N-G (2015). Mountain: A symbol of motherhood which expresses individuation. Journal of Symbols \& Sandplay Therapy (JSST), 6(1), 55-68.

Lee, B-H \& Lee, Y-J (2009). Selected poems of the Tang Dynasty (唐詩選). Seoul National University Publishing Council.

Rhi, B-Y (1995). In-depth analysis of Korean folklore. Gyeonggi: Jibmundang

Rhi, B-Y (2001). Anima and animas. Seoul: Hangilsa.

Rhi, B-Y (2002). Self and Self realization. Seoul: Hangilsa.

Lee, S-H (2004). Korean culture through flowers Vol. 3. Seoul: Nexus Co.Ltd.

Lee, S-J (1590/2018). Compendium of Materia Medica (Bonchogangmok). (Translated in 2018 by Korean National Medical Research). Seoul: Munsacheol.

Lee, C-B (1982). Illustrated Flora of Korea. Gyeonggi: Hyangmunsa.

Lee, H-O and Gu, Y-S, (2012). Aesthetic characteristics of facial expressions in the late Joseon Dynasty's beauty paintings. Fashion and Textiles Research Journal, 14(6), 918-927.

Lim, B-G (1986). A study on spacing patterns of sperm tree in Korean rural villages. Seoul 
National University, Graduate School of Environmental Studies Dissertation

Jeong, D-J (1397/2009). Sambongjip (Collected Works of Jeong Do-jeon) - Volume 1 (Trans. into

Korean by Jang, Byeong-Cheol in 2009. Seoul: Korean Studies Information).

Jang, M-K (2013). Analytical psychological meaning of masks in the Hahoe Pyolshin Gut

Tal(Mask) Play Dance in Korea. Journal of Symbols \& Sandplay Therapy (JSST), 4(1), 16-20.

Jang, M-K (2017). Psychological analysis of sandplay therapy. Seoul: Hakjisa Publisher.

Choi, H-Y (2008). The possibility of local cultural exchange in Eurasia through the sharing of mythological elements of the willow tree or other aspects. North East History Foundation Journal (Dongbuga yeoksa Nonchong), 22, 187-217.

Hyeon, Y-J (1980). Jeju Island Shaman Dictionary. Seoul: Shingu Media and Publishing

\section{Translated works:}

Edinger, E. (1972/2016). Ego and archetype. (Trans. into Korean in 2016 by Jang, Mikyung, Hakjisa Publisher, Inc.: Seoul).

Tresidder, J (2000/2007). Symbols and their meanings. (Trans. into Korean in 2007 by Kim, Byeong-Hwa. Seoul Dosol School).

Jung, C. G. (1963/1989). Mysterium coniunctionis. CW 14. Bollingen Series XX. Princeton, NJ: Princeton University Press.

Jung, C. G. (1984/2001). Grundfragen zur Praxis. Princeton: Bollingen/Princeton University Press. (Trans. into Korean in 2001 by Jung Institute of Korea).

Jung, C. G. (1984/2002). Archetyp und Unbewustes. Princeton: Bollingen/Princeton University Press. (Trans. into Korean in 2002 by Jung Institute of Korea).

Jung, C. G. (1985/2006). Heros und Mutterrarchetype. Princeton: Bollingen/Princeton University Press. (Trans. into Korean in 2006 by Jung Institute of Korea).

Jung, C. G. (1984/2004). Persoonlichkeit und Ubertragung. Princeton: Bollingen/Princeton University Press. (Trans. into Korean in 2004 by Jung Institute of Korea).

Jung, C. G. (1985/2004). Erlosungsvorstellungen in der Alchemie. Princeton: Bollingen/Princeton University Press. (Trans. into Korean in 2004 by Jung Institute of Korea).

Kast, V. (1994). Father-Daughter, Mother-Son: Freeing ourselves from the Complexes that Bbind us. 
Journal of Symbols \& Sandplay Therapy, Vol.10 No.1.

Seoul: Purme Publishing Co. (Trans, into Korean in 2010).

Neumann, E. (1973). The Child Mutter. Boston, MA: Shambhala.

Neumann, E. (1974). Die Grosse Mutter. Dusseldorf: Walter. (Trans, into Korean in 2007).

von Franz, M-L, (1981). Pure aetemus. Munchen: Sigo Press.

Woodman, M. (1990). The Ravaged Bridegroom. Toronto: Inner City Books

\section{Web sites}

"Why She Tried to Touch Me." Channel Yes. Modified on February 3, 2015. Visited on November 5, 2017, http://m.ch.yes24.com/Article/View/16861.

"The Willow." Character Club. Modified on July 8, 2016. Visited on November 5, 2017. http://blog.navercom/9010096?Redirect $=\log \& \log \mathrm{No}=50$.

"Lee Chang-Bok, The Willow." Encyclopedia of Korean Culture. Modified in 1995. Visited on March 2, 2018. http://encykorea.aks.ac.kr/.

"Inside the story of Yangpyeong Dumulmeori," Mountain Story Blog. Modified on June 12, 2018. Visited on September 11, 2018. https://blog.naver.com/singleway/221297493561

"Banghwasuryujeong in Hwaseong Fortress." Modified on June 20, 2014. Visited on November 3, 2017. http://blog.naver.com/kairai?Redirect-ghktjd

"Willows on the Lohas Walkway of the Daecheongho Lake." Modified on February 12, 2016. Visited on November 10, 2017. http://photo.naver.com/view/2012000812502858386

"Uses of the Willow Bark." Gunwi JuJube Hwagye Farm. Modified on April 5, 2014. Visited on October 20, 2017. http://blog.naver.com/pshkt3076?Redirect=Log.

"The Male Flower and Flower Bud of the Willow." The Medicinal Herb Guide. Modified on March 28, 2000. Visited on October 20, 2017. http://terms.naver.com/entry.nhn?dicId= 1995312

"Jeong Jin-Hee, Goddess of Mercy with a willow branch." Beopbo News. Modified on July 12, 2017. Visited on October 30, 2017. http://www.beopbo.com.

“Tree Stories by Professor Park Sang-jin 94." Yeongnam Daily. Modified on March 5, 2001. Visited on September 29, 2017. http://www.yeongnam.com./renew/common/printPage.jsp.

“Genre Painting by Sin Yun-bok." Ko Jae-hwan, Let's Go on a Trip. 
Kowen, Mee Ra / A Symbol of Healing with Feminine Vitality: The Willow

Modified on July 2, 2016. Visited on March 5, 2018. http://blog.naver.com/jawoh?Redirect.

"Woman Standing under the Willows." Meeting of National Museums, France (RMN).

Modified on December 1, 2017. Visited on December 11, 2017. http://terms.naver.com/ entry.nhn

“\#herbs \#willows \#catkins." Sansamnara. Modified on April 23 2017. Visited on December 5, 2017. https://blog.naver.com/yanjinet/ 220990340515

"Comparison of Winter Willow Twigs." The Medicinal Herb Guide. Modified on March 12, 1995. Visited on October 20, 2017. http://terms.naver.com/entry.nhn?docId=1995312 